\title{
Deuteron induced activation cross section measurement for IFMIF
}

\author{
K. Ochiai ${ }^{1, a}$, M. Nakao ${ }^{2}$, N. Kubota ${ }^{1, b}$, S. Sato ${ }^{1}$, M. Yamauchi ${ }^{1}$, N.H. Ishioka ${ }^{1}$, T. Nishitani ${ }^{1}$, and C. Konno ${ }^{1}$ \\ 1 Japan Atomic Energy Agency, Ibaraki 319-1195, Japan \\ 2 Kawasaki Plant Systems, Ltd., Tokyo 136-8588, Japan
}

\begin{abstract}
Deuteron irradiation experiments were performed to measure two kinds of data for IFMIF accelerator structural materials. One is a measurement of deuteron-induced activation cross sections for prospective candidate materials, i.e., aluminum, vanadium, chromium, manganese, iron, nickel, copper, tantalum, tungsten and gold, in the energy range of 14-49 MeV. The other is a measurement of deuteron-induced activities of nuclide produced in SS316 and F82 $\mathrm{H}$ by $39.5 \mathrm{MeV}$ deuteron. It is found that most measured cross sections correspond with TALYS calculations rather than ACSELAM and it is confirmed that the activities in SS316 and F82H can be nearly evaluated within the accuracy of the experimental errors by using the present measured cross section data.
\end{abstract}

\section{Introduction}

The International Fusion Materials Irradiation Facility (IFMIF) [1] is an accelerator-based D-Li neutron source designed to produce an intense neutron field for testing fusion reactor candidate materials. The IFMIF has two $40 \mathrm{MeV}$ deuteron linear accelerators with each $125 \mathrm{~mA}$ beam current. In this work, we performed deuteron irradiation experiments to measure two kinds of data for IFMIF accelerator structural materials. One is a measurement of deuteron-induced activation cross sections for pure metal materials, i.e., aluminum, vanadium, chromium, manganese, iron, nickel, copper, tantalum, tungsten and gold, in the energy range of $14-49 \mathrm{MeV}$. Measured activation cross section data were also compared with previous experimental data measured by other groups and two types of calculations. The other is a measurement of deuteron-induced activities of nuclide produced in SS316 and $\mathrm{F} 82 \mathrm{H}$ by $39.5 \mathrm{MeV}$ deuteron for the comprehensive verification of the measured activation cross sections with pure materials.

\section{Experiment}

The deuteron irradiation experiment was performed at a station of an AVF cyclotron in the Takasaki Ion accelerators for Advanced Radiation Application (TIARA) facility. In this experiment, we adopted a stacked-foil activation technique to measure cross sections at different energy points simultaneously [2]. Sample foils were stacked in order of $\mathrm{Ta}, \mathrm{Ni}, \mathrm{Fe}$, V, Ta, Ni, Fe, V, Ta, Ni, Fe, V, Ta, Ni, Fe, V, Ta, Ni, Fe and $\mathrm{Cu}$. Each foil with thicknesses of $10-200 \mu \mathrm{m}$ was cut into a $10 \mathrm{~mm}$ squared sample. The purities of pure metal foils were more than $99 \%$. The samples wrapped in an aluminum cover of $10 \mu \mathrm{m}$ in thickness were set in the stack folder, which was held with an aluminum stopper of $100 \mu \mathrm{m}$ in thickness. The stacked-foil was irradiated with the deuteron beam on normal incidence with the current of $0.1 \mu \mathrm{A}$ (beam spot size: $8 \mathrm{~mm}$ in diameter) during 2-7 minutes. Incident energies of

${ }^{a}$ Presenting author, e-mail: ochiai.kentaro@jaea.go.jp

${ }^{b}$ Present address: NIPPON STEEL CORPORATION, Japan
Table 1. Measured activation cross sections.

\begin{tabular}{|c|c|c|c|}
\hline $\begin{array}{l}{ }^{27} \mathrm{Al}(\mathrm{d}, \mathrm{x}){ }^{22} \mathrm{Na}, \\
{ }^{n a t} \mathrm{Cr}(\mathrm{d}, \mathrm{x}){ }^{48} \mathrm{~V}, \\
{ }^{n a t} \mathrm{Fe}(\mathrm{d}, \mathrm{x}){ }^{54} \mathrm{Mn}, \\
{ }^{n a t} \mathrm{Ni}(\mathrm{d}, \mathrm{x}){ }^{55} \mathrm{Co}, \\
{ }^{\text {nat }} \mathrm{Ni}(\mathrm{d}, \mathrm{x}){ }^{61} \mathrm{Cu}, \\
{ }^{n a t} \mathrm{Cu}(\mathrm{d}, \mathrm{x}){ }^{64} \mathrm{Cu}, \\
{ }^{n a t} \mathrm{~W}(\mathrm{~d}, \mathrm{x}){ }^{182} \mathrm{Re}, \\
{ }^{\text {nat }} \mathrm{W}(\mathrm{d}, \mathrm{x}){ }^{187} \mathrm{~W},\end{array}$ & $\begin{array}{l}{ }^{27} \mathrm{Al}(\mathrm{d}, \mathrm{x}){ }^{24} \mathrm{Na}, \\
{ }^{n a t} \mathrm{Cr}(\mathrm{d}, \mathrm{x}){ }^{52} \mathrm{Mn}, \\
{ }^{n a t} \mathrm{Fe}(\mathrm{d}, \mathrm{x}){ }^{55} \mathrm{Co}, \\
{ }^{n a t} \mathrm{Ni}(\mathrm{d}, \mathrm{x}){ }^{57} \mathrm{Co}, \\
{ }^{n a t} \mathrm{Cu}(\mathrm{d}, \mathrm{x}){ }^{62} \mathrm{Zn}, \\
{ }^{\text {nat }} \mathrm{Ta}(\mathrm{d}, \mathrm{x}){ }^{178} \mathrm{Ta}, \\
{ }^{\text {nat }} \mathrm{W}(\mathrm{d}, \mathrm{x}){ }^{183} \mathrm{Re}, \\
{ }^{197} \mathrm{Au}(\mathrm{d}, \mathrm{x}){ }^{194} \mathrm{Au}\end{array}$ & $\begin{array}{l}{ }^{27} \mathrm{Al}(\mathrm{d}, 2 \mathrm{p}){ }^{27} \mathrm{Mg}, \\
{ }^{55} \mathrm{Mn}(\mathrm{d}, \mathrm{x}){ }^{54} \mathrm{Mn}, \\
{ }^{n a t} \mathrm{Fe}(\mathrm{d}, \mathrm{x}){ }^{56} \mathrm{Co}, \\
{ }^{n a t} \mathrm{Ni}(\mathrm{d}, \mathrm{x}){ }^{56} \mathrm{Co}, \\
{ }^{n a t} \mathrm{Cu}(\mathrm{d}, \mathrm{x}){ }^{63} \mathrm{Zn}, \\
{ }^{\text {nat }} \mathrm{Ta}(\mathrm{d}, \mathrm{x}){ }^{180} \mathrm{Ta}, \\
{ }^{\text {nat }} \mathrm{W}(\mathrm{d}, \mathrm{x}){ }^{184} \mathrm{Re},\end{array}$ & $\begin{array}{l}{ }^{51} \mathrm{~V}(\mathrm{~d}, 4 \mathrm{n}){ }^{49} \mathrm{Cr}, \\
{ }^{n a t} \mathrm{Fe}(\mathrm{d}, \mathrm{x}){ }^{52} \mathrm{Mn}, \\
{ }^{\text {nat }} \mathrm{Fe}(\mathrm{d}, \mathrm{x}){ }^{57} \mathrm{Co}, \\
{ }^{n a t} \mathrm{Ni}(\mathrm{d}, \mathrm{x}){ }^{60} \mathrm{Cu}, \\
{ }^{n a t} \mathrm{Cu}(\mathrm{d}, \mathrm{x}){ }^{61} \mathrm{Cu}, \\
{ }^{\text {nat }} \mathrm{W}(\mathrm{d}, \mathrm{x}){ }^{181} \mathrm{Re}, \\
{ }^{\text {nat }} \mathrm{W}(\mathrm{d}, \mathrm{x}){ }^{186} \mathrm{Re},\end{array}$ \\
\hline
\end{tabular}

$25,35,41$ and $50 \mathrm{MeV}$ were chosen. After the irradiation and suitable cooling time, gamma-rays emitted from the irradiated samples were measured by a high-purity germanium detector. The total error of the measured activation cross sections was 10-20\% except some of cases. In the same way, activities of nuclides produced in SS316 and F82H foils with $100 \mu \mathrm{m}$ thickness were measured with $39.5 \mathrm{MeV}$ deuteron (incident energy: $41 \mathrm{MeV}$ ).

\section{Results and discussions}

We have measured activation cross sections of 30 reactions induced with deuteron in the energy range of $14-49 \mathrm{MeV}$ from $\mathrm{Al}, \mathrm{V}, \mathrm{Fe}, \mathrm{Cr}, \mathrm{Mn}, \mathrm{Ni}, \mathrm{Cu}, \mathrm{Ta}, \mathrm{W}$ and Au. Table 1 shows the measured activation cross sections.

Some of our results are introduced in section 3.1-3.9. Activation cross section data measured in this work were compared with previous experimental data measured by other groups and two types of calculation ones. Data in the EXFOR database [3] were cited as the previous experimental data. Calculation values were the data library (ACSELAM) [4] computed with the ALICE-F code [5] and were computed by the TALYS code (ver. 0.64A) and default parameters [6]. Since both the calculated values were given for each isotope, data normalized with weighting with natural abundance were used for the comparison. In section 3.10, the result of activations in SS316 and F82H alloys is described. 


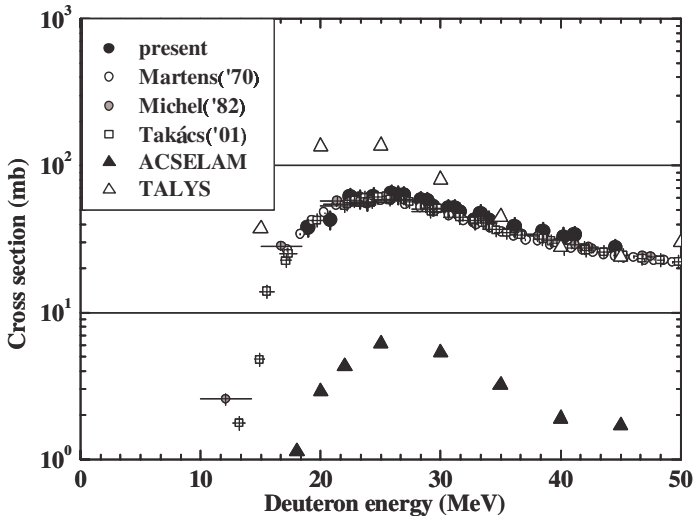

Fig. 1. Cross section for the ${ }^{27} \mathrm{Al}(\mathrm{d}, \mathrm{x})^{24} \mathrm{Na}$ reaction.

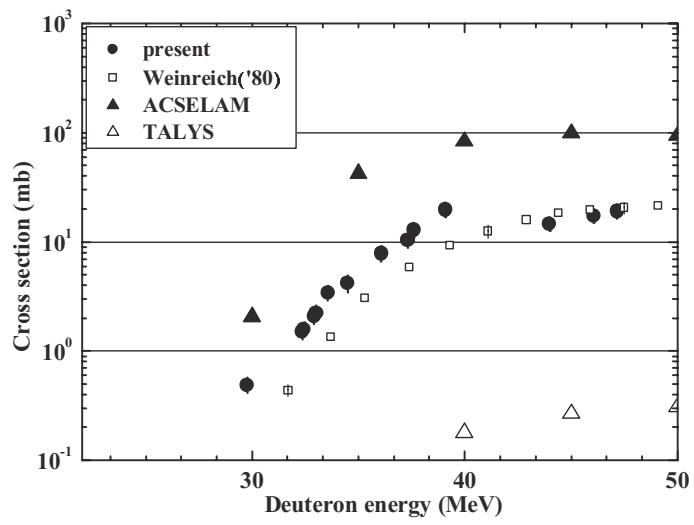

Fig. 2. Cross section for the ${ }^{51} \mathrm{~V}(\mathrm{~d}, 4 \mathrm{n}){ }^{49} \mathrm{Cr}$ reaction.

\section{$3.1{ }^{27} \mathrm{Al}(\mathrm{d}, \mathrm{x})^{24} \mathrm{Na}$}

The cross sections of the ${ }^{27} \mathrm{Al}(\mathrm{d}, \mathrm{x})^{24} \mathrm{Na}$ reaction are shown in figure 1. The present data correspond with the previous ones by Martens et al. [7], Michel et al. [8] and Takács et al. [9] within 40\%. ACSELAM is smaller than the present data by a factor of 13 . TALYS is in good agreement with the present data above $35 \mathrm{MeV}$ and is larger than the present data by a factor of 2-3 below $30 \mathrm{MeV}$.

\section{$3.2{ }^{51} \mathrm{~V}(\mathrm{~d}, 4 \mathrm{n}){ }^{49} \mathrm{Cr}$}

The ${ }^{51} \mathrm{~V}(\mathrm{~d}, 4 \mathrm{n}){ }^{49} \mathrm{Cr}$ reaction cross section has been measured, as shown in figure 2. Weinreich et al. [10] only reported the data of this reaction above $32 \mathrm{MeV}$, which is smaller than the present data by a factor of 2. ACSELAM is larger than the present data by a factor of 4-6. TALYS is smaller than the present data by 2 orders of magnitude.

\section{$3.3^{\text {nat }} \mathrm{Fe}(\mathrm{d}, \mathrm{x}){ }^{54} \mathrm{Mn}$ and ${ }^{\text {nat }} \mathrm{Fe}(\mathrm{d}, \mathrm{x})^{56} \mathrm{Co}$}

Figures 3 and 4 show the cross section of nat $\mathrm{Fe}(\mathrm{d}, \mathrm{x})^{54} \mathrm{Mn}$ and ${ }^{\text {nat }} \mathrm{Fe}(\mathrm{d}, \mathrm{x}){ }^{56} \mathrm{Co}$, respectively. Natural iron of ${ }^{54} \mathrm{Fe}(5.81 \%)$, ${ }^{56} \mathrm{Fe}(91.72 \%),{ }^{57} \mathrm{Fe}(2.21 \%)$ and ${ }^{58} \mathrm{Fe}(0.28 \%)$ was used. For the ${ }^{\text {nat }} \mathrm{Fe}(\mathrm{d}, \mathrm{x})^{54} \mathrm{Mn}$ reaction, the present data agree with the previous experimental data within $50 \%$. ACSELAM is smaller

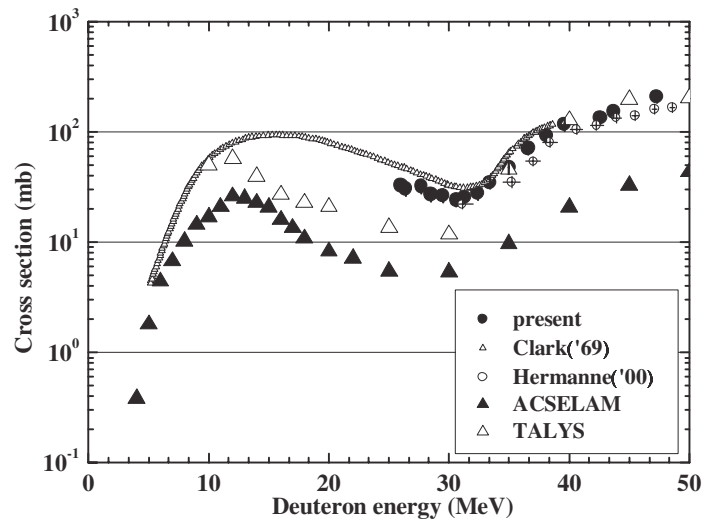

Fig. 3. Cross section for the ${ }^{\text {nat }} \mathrm{Fe}(\mathrm{d}, \mathrm{x})^{54} \mathrm{Mn}$ reaction.

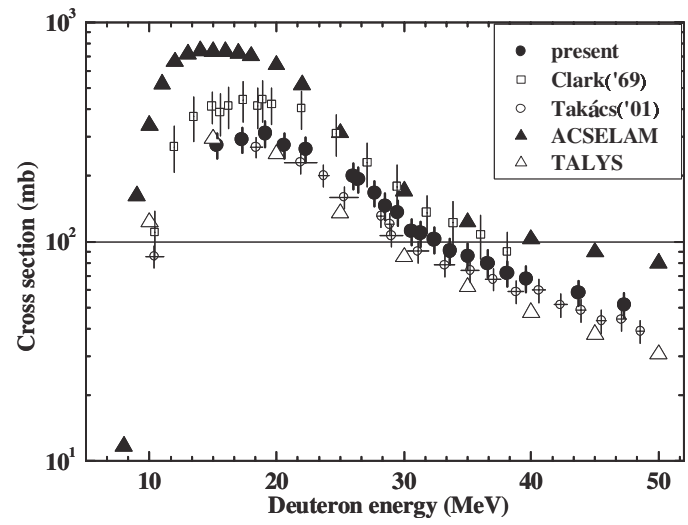

Fig. 4. Cross section for the ${ }^{\text {nat }} \mathrm{Fe}(\mathrm{d}, \mathrm{x}){ }^{56} \mathrm{Co}$ reaction.

than the present data by a factor of 5. TALYS is in good agreement with the present data above $35 \mathrm{MeV}$ and is smaller than the present data by a factor of 3 below $30 \mathrm{MeV}$. For the ${ }^{\text {nat }} \mathrm{Fe}(\mathrm{d}, \mathrm{x})^{56} \mathrm{Co}$ reaction, the present data agree with the Clark's ones [11] above $27 \mathrm{MeV}$ and the Takács's ones [9]. ACSELAM is larger than the present data by a factor of 2 and TALYS corresponds with the present data within $50 \%$.

\section{$3.4{ }^{\text {nat }} \mathrm{Ni}(\mathrm{d}, \mathrm{x})^{57} \mathrm{Co}$}

Figure 5 shows the cross sections of the ${ }^{\text {nat }} \mathrm{Ni}(\mathrm{d}, \mathrm{x})^{57} \mathrm{Co}$ reaction in natural nickel: ${ }^{58} \mathrm{Ni}(68.08 \%),{ }^{60} \mathrm{Ni}(26.22 \%),{ }^{61} \mathrm{Ni}$ $(1.14 \%),{ }^{62} \mathrm{Ni}(3.63 \%)$. The previous data, Cline et al. [12] and Takács [9], and TALYS correspond with the present data within $40 \%$ and $80 \%$, respectively. ACSELAM is smaller than the present data by a factor of 2-4.

\section{$3.5^{\text {nat }} \mathrm{Cu}(\mathrm{d}, \mathrm{x}){ }^{63} \mathrm{Zn}$}

Natural copper, ${ }^{63} \mathrm{Cu}(69.17 \%)$ and ${ }^{65} \mathrm{Cu}(30.83 \%)$, was used. The measured cross sections of the ${ }^{\text {nat }} \mathrm{Cu}(\mathrm{d}, \mathrm{x})^{63} \mathrm{Zn}$ reaction is shown in figure 6 . The previous data were reported by Bartell et al. [13] and Fulmer et al. [14]. Fulmer's data are larger than the present ones by a factor of 2. ACSELAM corresponds with the present data within $40 \%$. TALYS is smaller than the present data by a factor of 2-3. 


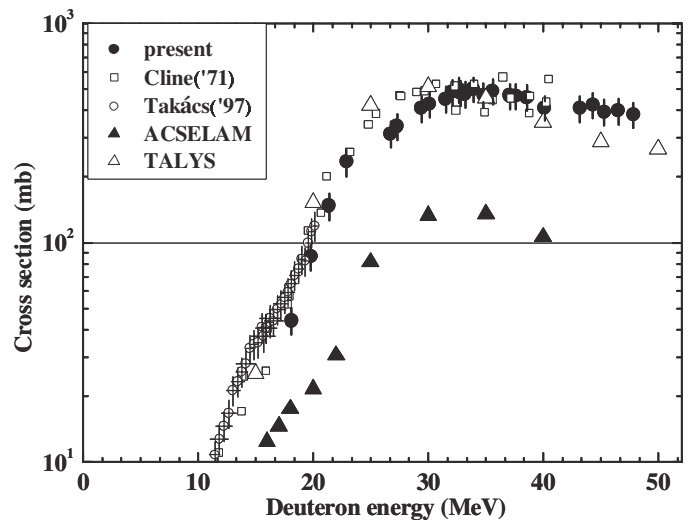

Fig. 5. Cross section for the ${ }^{\text {nat }} \mathrm{Ni}(\mathrm{d}, \mathrm{x})^{57} \mathrm{Co}$ reaction.

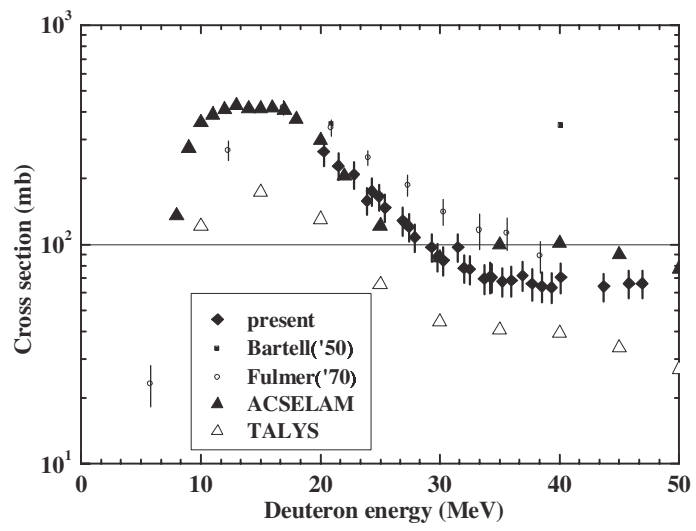

Fig. 6. Cross section for the ${ }^{\text {nat }} \mathrm{Cu}(\mathrm{d}, \mathrm{x})^{63} \mathrm{Zn}$ reaction.

\section{$3.6^{\text {nat }} \mathrm{Ta}(\mathbf{d}, \mathbf{x})^{180} \mathrm{Ta}$}

The cross sections of the ${ }^{\text {nat }} \mathrm{Ta}(\mathrm{d}, \mathrm{x})^{180} \mathrm{Ta}$ reactions was measured as shown in figure 7. There is no previous experimental data for this reaction. ACSELAM and TALYS are half of the present data.

\section{$3.7^{\text {nat }} \mathrm{W}(\mathrm{d}, \mathrm{x})^{182} \mathrm{Re}$}

Natural tungsten composed of ${ }^{180} \mathrm{~W}(0.12 \%),{ }^{182} \mathrm{~W}(26.50 \%)$, ${ }^{183} \mathrm{~W}(14.31 \%),{ }^{184} \mathrm{~W}(30.64 \%)$ and ${ }^{186} \mathrm{~W}(28.43 \%)$ was used. Figure 8 shows the cross sections of both ${ }^{\text {nat }} \mathrm{W}(\mathrm{d}, \mathrm{x})^{182 \mathrm{~m}} \mathrm{Re}$ and ${ }^{n a t} \mathrm{~W}(\mathrm{~d}, \mathrm{x})^{182 \mathrm{~g}} \mathrm{Re}$ reactions. The present data of both reactions are in good agreement with the data reported by Tárkányi et al. [15]. ACSELAM and TALYS correspond with the present data within $50 \%$.

\section{$3.8{ }^{197} \mathrm{Au}(\mathrm{d}, \mathrm{x}){ }^{194} \mathrm{Au}$}

The cross section of the ${ }^{197} \mathrm{Au}(\mathrm{d}, \mathrm{x}){ }^{194} \mathrm{Au}$ reaction is shown in figure 9. No previous results are found in literatures. ACSELAM and TALYS agree with the present data within $60 \%$.

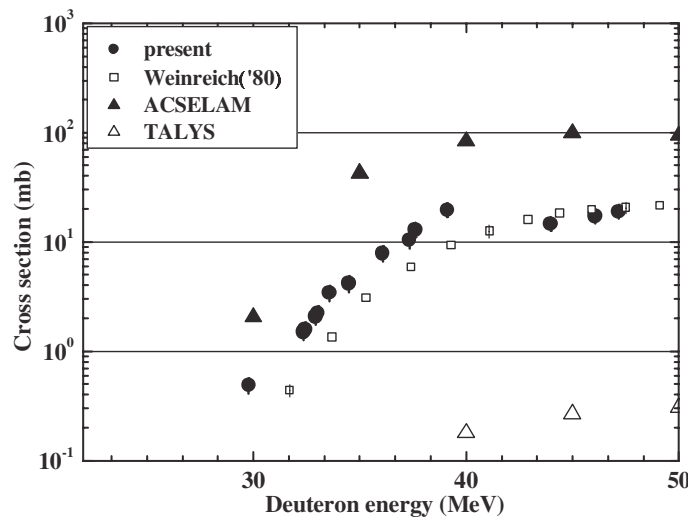

Fig. 7. Cross section for the ${ }^{\text {nat }} \mathrm{Ta}(\mathrm{d}, \mathrm{x})^{180} \mathrm{Ta}$ reaction.

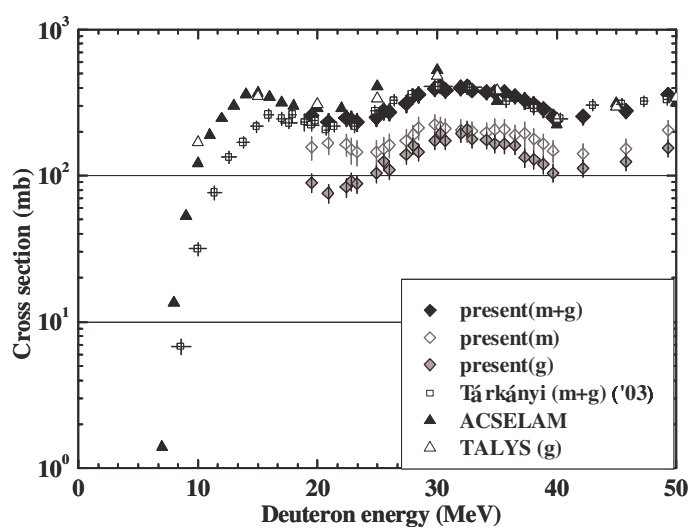

Fig. 8. Cross section for the ${ }^{\text {nat }} \mathrm{W}(\mathrm{d}, \mathrm{x})^{182}$ Re reaction.

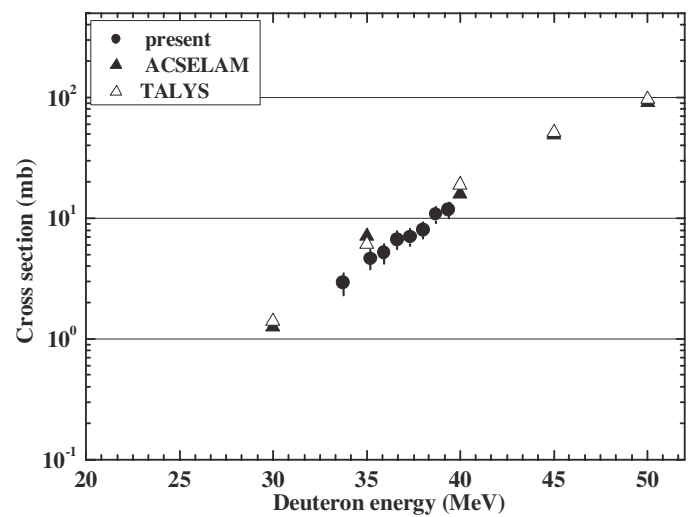

Fig. 9. Cross section for the ${ }^{197} \mathrm{Au}(\mathrm{d}, \mathrm{x}){ }^{194} \mathrm{Au}$ reaction.

\section{$3.9^{\text {nat }} \mathrm{Cr}(\mathrm{d}, \mathrm{x})^{48} \mathrm{~V},{ }^{\text {nat }} \mathrm{Cr}(\mathrm{d}, \mathrm{x})^{52} \mathrm{Mn},{ }^{55} \mathrm{Mn}(\mathrm{d}, \mathrm{x})^{54} \mathrm{Mn}$ and ${ }^{\text {nat }} \mathrm{Ni}(\mathbf{d}, \mathbf{x})^{56} \mathrm{Co}$}

In order to evaluate the activities of SS316 and F82H alloys by $39.5 \mathrm{MeV}$ deuteron irradiation, the cross sections of ${ }^{\text {nat }} \mathrm{Cr}(\mathrm{d}, \mathrm{x}){ }^{48} \mathrm{~V},{ }^{52} \mathrm{Mn},{ }^{55} \mathrm{Mn}(\mathrm{d}, \mathrm{x}){ }^{54} \mathrm{Mn}$ and ${ }^{\text {nat }} \mathrm{Ni}(\mathrm{d}, \mathrm{x}){ }^{56} \mathrm{Co}$ reactions were measured. Table 2 shows the measured cross sections and calculated ones for the ${ }^{\text {nat }} \mathrm{Cr}(\mathrm{d}, \mathrm{x})^{48} \mathrm{~V},{ }^{52} \mathrm{Mn}$, ${ }^{55} \mathrm{Mn}(\mathrm{d}, \mathrm{x}){ }^{54} \mathrm{Mn}$ and ${ }^{\text {nat }} \mathrm{Ni}(\mathrm{d}, \mathrm{x}){ }^{56} \mathrm{Co}$ reactions by $39.5 \mathrm{MeV}$ deuterons. TALYS calculations corresponded with the present values within $65 \%$ 
Table 2. Cross section for the ${ }^{\text {nat }} \mathrm{Cr}(\mathrm{d}, \mathrm{x}){ }^{48} \mathrm{~V},{ }^{52} \mathrm{Mn},{ }^{55} \mathrm{Mn}(\mathrm{d}, \mathrm{x}){ }^{54} \mathrm{Mn}$ and ${ }^{\text {nat }} \mathrm{Ni}(\mathrm{d}, \mathrm{x}){ }^{56} \mathrm{Co}$ reactions.

\begin{tabular}{lccl}
\hline Reaction & cross section $(\mathrm{mb})$ & & ratio \\
\cline { 2 - 4 }$\left(\mathrm{E}_{\mathrm{d}}=39.5 \mathrm{MeV}\right)$ & present (error) & TALYS & TAL/present \\
\hline${ }^{\text {nat }} \mathrm{Cr}(\mathrm{d}, \mathrm{x})^{48} \mathrm{~V}$ & $69.3(9.8)$ & 47.9 & 0.69 \\
${ }^{\mathrm{nat}} \mathrm{Cr}(\mathrm{d}, \mathrm{x})^{52} \mathrm{Mn}$ & $48.0(6.6)$ & 68.2 & 1.42 \\
${ }^{55} \mathrm{Mn}(\mathrm{d}, \mathrm{x}){ }^{54} \mathrm{Mn}$ & $507.4(68.6)$ & 342.5 & 0.68 \\
${ }^{\text {nat }} \mathrm{Ni}(\mathrm{d}, \mathrm{x})^{56} \mathrm{Co}$ & $88.4(11.9)$ & 146.2 & 1.65 \\
\hline
\end{tabular}

Table 3. Deuteron induced activities of nuclides produced in SS316.

\begin{tabular}{lcccl}
\hline product & target & $\begin{array}{c}\text { meas. (error\%) } \\
\left(\mathrm{kBq} / \mathrm{cm}^{3}\right)\end{array}$ & eval. & $\begin{array}{l}\text { SS316 } \\
\text { eval./meas. }\end{array}$ \\
\hline${ }^{48} \mathrm{~V}$ & ${ }^{\text {nat }} \mathrm{Cr}$ & 46.2 & 47.1 & 1.02 \\
${ }^{52} \mathrm{Mn}$ & ${ }^{\text {nat }} \mathrm{Cr},{ }^{\text {nat }} \mathrm{Fe}$ & 500.4 & 515.4 & 1.03 \\
${ }^{54} \mathrm{Mn}$ & ${ }^{55} \mathrm{Mn}$, ${ }^{\text {nat }} \mathrm{Fe}$ & 13.7 & 14.5 & 1.06 \\
${ }^{56} \mathrm{Co}$ & ${ }^{\text {nat }} \mathrm{Fe},{ }^{\text {nat }} \mathrm{Ni}$ & 40.0 & 42.0 & 1.05 \\
${ }^{57} \mathrm{Co}$ & ${ }^{\text {nat }} \mathrm{Fe},{ }^{\text {nat }} \mathrm{Ni}$ & 17.8 & 17.4 & 0.98 \\
\hline
\end{tabular}

Table 4. Deuteron induced activities nuclides produced in F82H.

\begin{tabular}{lcccl}
\hline product & target & $\begin{array}{c}\text { meas. (error\%) } \\
\left(\mathrm{kBq} / \mathrm{cm}^{3}\right)\end{array}$ & eval. & $\begin{array}{l}\mathrm{F} 82 \mathrm{H} \\
\text { eval./meas. }\end{array}$ \\
\hline${ }^{48} \mathrm{~V}$ & ${ }^{\text {nat }} \mathrm{Cr}$ & 20.7 & 21.9 & 1.06 \\
${ }^{52} \mathrm{Mn}$ & ${ }^{\text {nat }} \mathrm{Cr},{ }^{\text {nat }} \mathrm{Fe}$ & 585.8 & 630.9 & 1.08 \\
${ }^{54} \mathrm{Mn}$ & ${ }^{55} \mathrm{Mn},{ }^{\text {nat }} \mathrm{Fe}$ & 14.3 & 18.5 & 1.29 \\
${ }^{56} \mathrm{Co}$ & ${ }^{\text {nat }} \mathrm{Fe},{ }^{\text {nat }} \mathrm{Ni}$ & 42.9 & 48.0 & 1.12 \\
${ }^{57} \mathrm{Co}$ & ${ }^{n a t} \mathrm{Fe},{ }^{\text {nat }} \mathrm{Ni}$ & 5.4 & 5.6 & 1.04 \\
${ }^{181} \mathrm{Re}$ & ${ }^{\text {nat }} \mathrm{W}$ & 213.0 & 229.2 & 1.08 \\
\hline
\end{tabular}

\subsection{Activities of SS316 and F82H}

Tables 3 and 4 show deuteron induced activity of each nuclide produced in SS316 and F82H by $39.5 \mathrm{MeV}$ deuterons, respectively. The evaluated activities are derived from the cross section measured in the present experiment. The experimental error was estimated about $15 \%$. The evaluated activities of ${ }^{48} \mathrm{~V},{ }^{52} \mathrm{Mn},{ }^{55} \mathrm{Co},{ }^{56} \mathrm{Co},{ }^{57} \mathrm{Co}$ in the both alloys, ${ }^{54} \mathrm{Mn}$ in SS316 and ${ }^{181} \mathrm{Re}$ in $\mathrm{F} 82 \mathrm{H}$ are in agreement with the measured ones within the experimental error, whereas that of ${ }^{54} \mathrm{Mn}$ in $\mathrm{F} 82 \mathrm{H}$ overestimated by about $29 \%$. Further consideration is needed for the activity of ${ }^{54} \mathrm{Mn}$ in $\mathrm{F} 82 \mathrm{H}$.

\section{Summary}

Cross section data of 30 deuteron-induced reactions for pure metals used as IFMIF accelerator structural materials were measured within the accuracy of $10 \sim 20 \%$. TALYS is closer to the present data than ACSELAM for most reactions. For the comprehensive verification of the present measured cross sections, we have measured and evaluated activities of nuclide induced by deuteron of $39.5 \mathrm{MeV}$ in SS316 and F82H. It is confirmed that the induced activity in SS316 and F82H can be nearly evaluated within the accuracy of the experimental errors by using the present measured cross section data.

\section{References}

1. IFMIF International Team, JAERI-Tech 2003-005 (2003).

2. K. Ochiai, M. Nakao, J. Hori, S. Sato, M. Yamauchi, N.S. Ishioka, T. Nishitani, Fus. Eng. Des. 81, 1459 (2006).

3. For example: http://www.nndc.bnl.gov/exfor7/exfor00.htm.

4. N. Yamano, Table of Isotope Production Cross Sections (ACSELAM Library), in website of JAEA Nuclear Data Center: http://wwwndc.tokai-sc.jaea.go.jp/ftpnd/sae/acl.html.

5. T. Fukahori, Proc. of the Specialists' Meeting on High Energy Nuclear Data, Tokai, Oct. 3-4, 1991, JAERI-M 92-039 (1992), p. 114.

6. A.J. Koning, S. Hilaire, M. Duijvestijn, NRG Report 21297/04.62741/P (2004).

7. U. Martens, G.W. Schweimer, Zeitschrift für Physik 233, 170 (1970).

8. R. Michel, G. Brinkmann, M. Galas, R. Stuck, EXFOR No. A0158 (1982).

9. A. Hermanne, M. Sonck, S. Takács, F. Tárkányi, Nucl. Instrum. Meth. B 161-163, 178 (2000).

10. R. Weinreich, H.J. Probst, S.M. Qaim, Int. J. Appl. Radiat. Isot. 31, 223 (1980).

11. J.W. Clark, C.B. Fulmer, I.R. Williams, Phys. Rev. 179, 1104 (1969).

12. C.K. Cline et al., Nucl. Phys. A 174, 73 (1971).

13. F.O. Bartell, A.C. Helmholz, S.D. Softky, D.B. Stewart, Phys. Rev. 80, 1006 (1950).

14. C.B. Fulmer, I.R. Williams, Nucl. Phys. A 155, 40 (1970).

15. F. Tárkányi, S. Takács, F. Szelecsényi, F. Ditroi, A. Hermanne, M. Sonck, Nucl. Instrum. Meth. B 211, 319 (2003). 